\title{
Lymphatic vessel density and its prognostic value in stage I colorectal carcinoma
}

\author{
V Barresi, ${ }^{1}$ L Reggiani-Bonetti, ${ }^{2}$ C Di Gregorio, ${ }^{3}$ M Ponz De Leon, ${ }^{2}$ G Barresi ${ }^{1}$
}

'Department of Human Pathology, University of Messina, Messina, Italy ${ }^{2}$ Unit of Anatomic Pathology, Hospital of Carpi, Carpi, Italy ${ }^{3}$ Department of Medicine and Medical Specialities, University of Modena and Reggio-Emilia, Modena, Italy

\section{Correspondence to}

Dr Valeria Barresi, Dipartimento di Patologia Umana, Policlinico Universitario G. Martino, Pad D, Via Consolare Valeria, 98125

Messina, Italy;

vbarresi@unime.it

Dedicated to my daughter, Arianna, who was born on 25 July 2010.

Accepted 15 September 2010 Published Online First 14 October 2010

\section{ABSTRACT}

Aims The assessment of lymphatic vessel density (LVD) has been suggested as a tool to determine the metastatic risk of neoplasias. On this premise, the authors aimed to verify whether progression risk of stage I colorectal cancer may be related to LVD. The authors also evaluated and correlated vascular endothelial growth factor (VEGF)-A expression with LVD revealed in the same cases in order to investigate its potential lymphangiogenic role in the early stage colorectal cancer.

Methods LVD and VEGF immunoexpression were analysed and compared in series of 29 stage I surgically resected colorectal carcinomas obtained from patients showing disease progression and in a cohort of 23 stage I colorectal cancers from patients with no evidence of disease progression. The prognostic value of LVD and of VEGF expression on the progression-free survival to colorectal cancer was investigated.

Results A high density of peritumoural lymphatics (P-LVD) was significantly associated with high VEGF expression and disease progression. Moreover, high P-LVD and high VEGF expression were significant negative prognostic parameters associated with a shorter disease-free interval in stage I colorectal cancer. Conclusions If our findings are further confirmed in other studies, the assessment of P-LVD on surgical specimens might be used as a tool to identify patients with stage I colorectal cancer at higher risk of progression in order to submit them to adjuvant therapies. Since P-LVD seems to show a VEGF-A mediated regulation in stage I colorectal cancer, therapies targeting this factor might be exploited to reduce lymphangiogenesis and the progression risk of this neoplasia.

\section{INTRODUCTION}

Colorectal carcinoma is one of the leading causes of cancer death in Western Europe and in the USA. ${ }^{1}$ At present, postsurgical TNM staging system represents the most meaningful prognostic factor able to predict the clinical course of this neoplasia. ${ }^{2}{ }^{3}$ Stage I colorectal carcinoma indicates a neoplasm confined within the muscular wall of the large bowel without infiltration of local structures, in the absence of lymph nodes or distant metastases. It is characterised by a 5 -year survival rate of around $80-90 \%{ }^{145}$; by contrast, tumours of higher TNM stage show a 5 -year survival rate of only $25-60 \%{ }^{6}$ As a consequence, TNM staging is fully taken into consideration in the therapeutic protocols applied to colorectal cancer; thus, stage I colorectal carcinoma is treated by surgery alone, whereby adjuvant chemotherapy is applied in order to improve the survival of higher-stage carcinomas. Despite its proven prognostic value, ${ }^{23}$ in some instances TNM staging seems only to reflect the anatomical extent of the tumour with no correlation with the patients' survival, as disease progression with locoregional or distant metastases followed by adverse outcome has also been observed in a percentage of stage I colorectal carcinomas. ${ }^{4}$ Hence, the detection of novel histo-prognosic markers, in addition to the currently used clinical-pathological staging system, would be noteworthy to identify at the time of first diagnosis those patients with stage I colorectal cancer at high risk of progression in order to submit them to adjuvant therapies.

The lymphatic system is believed to be one of the most important pathways for tumour cell dissemination. Indeed, it is expected that tumour cells can enter lymphatic microvessels more easily than blood microvessels because the former show a discontinuous or completely absent basement membrane and are devoid of pericytes. ${ }^{7}$ Studies performed using specific markers for the lymphatic endothelial cells have shown that artificial induction of lymphangiogenesis in xenotransplanted human tumours is strongly associated with lymphatic tumour spread. ${ }^{8-10}$ Thus, it has been hypothesised that the assessment of lymphatic vessel density (LVD), which reflects tumorous lymphangiogenesis, might represent a tool to determine the metastatic risk of neoplasias. In light of this, LVD and lymphangiogenesis have been widely examined in colorectal carcinoma. ${ }^{11-19}$ An inverse significant correlation between LVD and cancer stage has been reported by some authors, ${ }^{13}$ suggesting that lymphangiogenesis may be involved in the earlier stage but not in the later stage of colorectal cancer development. ${ }^{13}$ Nevertheless, the prognostic value of LVD in stage I colorectal carcinoma still remains to be evaluated.

On this premise, in the present study we analysed and compared LVD in a subset of surgically resected stage I colorectal carcinomas from patients showing disease progression within 5 years from the initial diagnosis and in a cohort of stage I colorectal carcinomas from patients alive with no evidence of disease progression 5 years after curative surgery. With the aim of verifying whether any difference in LVD in the two groups might be at the basis of their divergent outcome, we also tested the prognostic significance of LVD on the progressionfree survival of the patients. Finally, as vascular endothelial growth factor-A (VEGF-A) has been suggested to play a lymphangiogenic action, ${ }^{20}$ we also evaluated and correlated its expression with LVD revealed in the same cases in order to 
investigate its potential lymphangiogenic role in the early stage colorectal cancer.

\section{MATERIALS AND METHODS}

The study was approved by local Ethics Committees. Informed consent was obtained from the patients prior to their inclusion in the study. Twenty-nine cases of surgically resected TNM stage I colorectal carcinomas characterised by disease progression during the follow-up were taken from the Cancer Registry of Modena, Italy and from the files of the Department of Human Pathology of the University of Messina, Italy. In all cases, progression was characterised by the development of metastatic (hepatic, osseous or pulmonary) disease.

Then, a comparable number of consecutive TNM stage I cases (23) with no evidence of disease progression or relapses after the initial diagnosis were considered among cases occurring during the same time period. The clinicopathological characteristics of selected cases are shown in table 1.

Pathological staging and histological grading of selected cases were performed on the basis of TNM system ${ }^{21}$ and WHO Classification system criteria, respectively.

Conservative local excision techniques for low rectal carcinomas had been applied in four cases and, specifically, in cases 40, 41, 44 and 47 (table 1). None of the patients had received chemotherapy for the neoplasia.

Finally, the cohort of the study included a total of 52 cases (30 male and 22 female patients; age range: $53-89$ years; mean age: 70 years).

\section{Immunohistochemistry}

All specimens had been fixed in 10\% neutral formalin for $24 \mathrm{~h}$ at room temperature, embedded in paraffin at $55^{\circ} \mathrm{C}$ and cut into parallel consecutive $4 \mu \mathrm{m}$ thick sections for the subsequent immunohistochemical study. Briefly, the endogenous peroxidase activity was blocked with $0.1 \% \mathrm{H}_{2} \mathrm{O}_{2}$ in methanol for $20 \mathrm{~min}$; then, normal sheep serum was applied for $30 \mathrm{~min}$ to prevent unspecific adherence of serum proteins. The D2-40 and VEGF antigens were unmasked by microwave oven pretreatment in $10 \mathrm{mM}$, pH 6.0 sodium citrate buffer for 3 cycles $\times 5 \mathrm{~min}$. Consecutive sections were successively incubated at $4^{\circ} \mathrm{C}$ overnight with the primary polyclonal antibody against VEGF sc152 (Santa Cruz Biotechnology, Santa Cruz, California; w.d. 1:100) and the monoclonal antibody against D2-40 (DAKO Corporation, Glostrup, Denmark, w.d. 1:200). The bound primary antibodies were visualised by the envision peroxidase detection system. To reveal the immunostaining, the sections were incubated in darkness for 10 min with 3-3' diaminobenzidine tetra hydrochloride (Sigma Chemical Co., St Louis, Missouri), in the amount of $100 \mathrm{mg}$ in $200 \mathrm{ml}$ of $0.03 \%$ hydrogen peroxide in phosphate-buffered saline solution (PBS). Nuclear counterstaining was performed by Mayer's haemalum. Specificity of the binding was assessed by omitting the primary antiserum or replacing it with normal rabbit serum or phosphate-buffered saline solution (PBS, pH 7.4). Moreover, normal renal tubules within specimens of kidney and the endothelial cells within specimens of lymphangioma were used as the positive controls for VEGF and D2-40 immunoreactions. ${ }^{22}$

\section{Quantification and statistics}

The assessment of immunostained section was performed by a random principle by two independent pathologists, blinded to the clinicopathological data. For each case, the number of cancer cells with cytoplasmic VEGF expression was assessed in all optical fields, and the median value was recorded as the VEGF score of the section. Cases displaying a score of 0 were considered negative for VEGF. The median score of the cohort was utilised as the cut-off value (VEGF score: 50) to define low (VEGF score $\leq 50$ ) and high (VEGF score >50) VEGF expression.

The quantification of LVD was performed as described by Weidner et al. ${ }^{23}$ The assessment was done within the cancerous mass, excluding all the necrotic and the ulcerated areas, as herein the presence of vessels may be related to inflammation rather than to the tumour itself. ${ }^{13}$ A microvessel was defined as a single endothelial cell or a cluster of endothelial cells positive for D2-40, located around a visible lumen clearly separate from adjacent microvessels and from other connective-tissue components. Additionally, as lymphatic vessels could generally appear as distorted and overlapped structures in a cancer setting, the packed vessels were assumed as one lymphatic unit.

Intra- and peritumoural D2-40 positive vessels were considered separately in order to define peritumoural (P-LVD) and intratumoural LVD (I-LVD). Intratumoural lymphatic vessels were defined as those within the tumour cell islets, and peritumoural lymphatics as those located at the peritumoural region near the tumour invasion margin. ${ }^{13}$

Briefly, the three most vascularised areas detected by D2-40 were initially selected (so-called hot spots) under a $40 \times$ field. Then, vessels were counted in each of these areas under a $400 \times$ field. The mean values of three $400 \times$ field $\left(0.30 \mathrm{~mm}^{2}\right)$ counts were recorded as the P-LVD or I-LVD of the section. Then, the P-LVD and I-LVD values were converted into the mean number of microvessels $/ \mathrm{mm}^{2}$ for the statistical analyses. The vessels were counted using a Zeiss microscope by two independent observers (VB and GB) blinded to the clinicopathological data.

Mann-Whitney and Kruskall-Wallis tests were performed in order to assess the statistical correlations between (intra- or peritumoural) LVD and the clinicopathological characteristics as well as VEGF expression of the tumours or the evidence of disease progression. In addition, a Spearman correlation test was carried out to verify the statistical correlation between LVD counts and VEGF scores.

Disease-free survival was assessed by the Kaplan-Meier method, with the date of primary surgery as the entry data. The end point was characterised as the length of survival to disease progression (metastatic disease) of colorectal carcinoma. The Mantel-Cox logrank test was applied to assess the strength of association between survival time and each of the parameters (age and gender of the patient, site, histological grade, T stage, VEGF immunoexpression and LVD of the tumour) as a single variable. Successively, a multivariate analysis (Cox regression model) was utilised to determine the independent effect of each significant variable.

The LVD median values (P-LVD median value: 10.54; I-LVD median value: 0 ) were used as the cut-off values to define low and high P-LVD and I-LVD for disease-free survival analyses.

A $p$ value of $<0.05$ was considered statistically significant. Data were analysed using the SPSS package version 6.1.3.

\section{RESULTS}

The clinicopathological characteristics as well as the LVD and VEGF immunoexpression of the 52 analysed stage I colorectal carcinomas are shown in tables 1,2 .

In all analysed cases, D2-40 antibody stained lymphatic but not haematic vessels (figure 1). Peritumoural D2-40 positive vessels were evidenced in $33 / 52$ cases with variable densities 
Table 1 Clinicopathological characteristics, lymphatic vessel density and vascular endothelial growth factor expression of the 52 analysed stage I colorectal carcimomas

\begin{tabular}{|c|c|c|c|c|c|c|c|c|c|c|}
\hline Case & Sex & Age & Site & Grade & $\mathbf{T}$ & $\begin{array}{l}\text { Intratumoural } \\
\text { lymphatic vessel } \\
\text { density }\left(\mathrm{v} / \mathrm{mm}^{2}\right)\end{array}$ & $\begin{array}{l}\text { Peritumoural } \\
\text { lymphatic vessel } \\
\text { density }\left(\mathrm{v} / \mathrm{mm}^{2}\right)\end{array}$ & $\begin{array}{l}\text { Vascular endothelial } \\
\text { growth factor } \\
\text { (percentage positive cells) }\end{array}$ & $\begin{array}{l}\text { Disease } \\
\text { progression }\end{array}$ & $\begin{array}{l}\text { Disease-free } \\
\text { interval } \\
\text { (months) }\end{array}$ \\
\hline 1 & $M$ & 63 & Left colon & 3 & 2 & 13.3 & 25.5 & 30 & No & 106 \\
\hline 2 & $\mathrm{M}$ & 62 & Right colon & 1 & 2 & 8.88 & 25.5 & 50 & No & 96 \\
\hline 3 & $\mathrm{M}$ & 58 & Left colon & 1 & 2 & 0 & 8.88 & 50 & No & 116 \\
\hline 4 & $\mathrm{M}$ & 71 & Right colon & 1 & 2 & 0 & 0 & 10 & No & 88 \\
\hline 5 & $\mathrm{M}$ & 55 & Left colon & 2 & 2 & 8.88 & 6.66 & 70 & No & 74 \\
\hline 6 & $\mathrm{M}$ & 75 & Right colon & 2 & 2 & 0 & 0 & 20 & No & 86 \\
\hline 7 & $\mathrm{M}$ & 62 & Right colon & 2 & 2 & 0 & 0 & 2 & No & 65 \\
\hline 8 & $\mathrm{~F}$ & 79 & Left colon & 2 & 2 & 0 & 15.5 & 100 & No & 78 \\
\hline 9 & $\mathrm{~F}$ & 83 & Right colon & 2 & 2 & 0 & 20 & 70 & No & 75 \\
\hline 10 & $\mathrm{~F}$ & 61 & Left colon & 2 & 2 & 10 & 0 & 30 & No & 61 \\
\hline 11 & $M$ & 62 & Left colon & 2 & 2 & 0 & 13.3 & 60 & No & 89 \\
\hline 12 & $\mathrm{~F}$ & 76 & Left colon & 2 & 2 & 0 & 0 & 60 & No & 90 \\
\hline 13 & $\mathrm{~F}$ & 64 & Left colon & 2 & 2 & 0 & 0 & 10 & No & 90 \\
\hline 14 & $M$ & 70 & Left colon & 2 & 2 & 0 & 8.88 & 20 & No & 82 \\
\hline 15 & $M$ & 79 & Left colon & 2 & 2 & 0 & 0 & 50 & No & 93 \\
\hline 16 & $\mathrm{~F}$ & 63 & Right colon & 3 & 2 & 0 & 0 & 80 & No & 77 \\
\hline 17 & $\mathrm{M}$ & 74 & Right colon & 2 & 2 & 0 & 0 & 30 & No & 98 \\
\hline 18 & $\mathrm{~F}$ & 85 & Left colon & 2 & 2 & 12.2 & 0 & 20 & No & 65 \\
\hline 19 & $\mathrm{~F}$ & 53 & Right colon & 2 & 2 & 0 & 4.44 & 25 & No & 110 \\
\hline 20 & $\mathrm{M}$ & 65 & Left colon & 2 & 2 & 6.66 & 0 & 10 & No & 106 \\
\hline 21 & $M$ & 86 & Right colon & 2 & 1 & 0 & 12.2 & 25 & No & 112 \\
\hline 22 & $\mathrm{~F}$ & 76 & Right colon & 2 & 2 & 0 & 8.88 & 25 & No & 105 \\
\hline 23 & $M$ & 69 & Left colon & 2 & 2 & 0 & 0 & 25 & No & 117 \\
\hline 24 & $M$ & 60 & Right colon & 1 & 2 & 10 & 15.5 & 50 & Yes & 58 \\
\hline 25 & $\mathrm{~F}$ & 66 & Right colon & 1 & 2 & 13.3 & 13.3 & 50 & Yes & 56 \\
\hline 26 & $\mathrm{~F}$ & 89 & Right colon & 1 & 2 & 0 & 0 & 30 & Yes & 28 \\
\hline 27 & $\mathrm{~F}$ & 71 & Right colon & 1 & 2 & 0 & 0 & 50 & Yes & 31 \\
\hline 28 & $\mathrm{~F}$ & 61 & Left colon & 2 & 2 & 11.1 & 16.6 & 100 & Yes & 24 \\
\hline 29 & $M$ & 71 & Right colon & 1 & 2 & 0 & 0 & 80 & Yes & 13 \\
\hline 30 & $M$ & 72 & Left colon & 1 & 2 & 8.88 & 25.5 & 100 & Yes & 40 \\
\hline 31 & $\mathrm{M}$ & 66 & Left colon & 1 & 2 & 0 & 25.5 & 100 & Yes & 12 \\
\hline 32 & $\mathrm{~F}$ & 60 & Left colon & 1 & 2 & 0 & 33.3 & 100 & Yes & 60 \\
\hline 33 & $\mathrm{~F}$ & 64 & Left colon & 2 & 2 & 0 & 7.77 & 100 & Yes & 60 \\
\hline 34 & $\mathrm{~F}$ & 55 & Left colon & 2 & 2 & 23.3 & 13.3 & 100 & Yes & 35 \\
\hline 35 & $\mathrm{M}$ & 69 & Right colon & 3 & 2 & 0 & 15.5 & 90 & Yes & 19 \\
\hline 36 & $\mathrm{M}$ & 77 & Left colon & 2 & 2 & 0 & 12.2 & 50 & Yes & 50 \\
\hline 37 & $\mathrm{~F}$ & 72 & Left colon & 2 & 2 & 7.77 & 35.5 & 100 & Yes & 41 \\
\hline 38 & $\mathrm{M}$ & 73 & Left colon & 2 & 1 & 0 & 0 & 50 & Yes & 16 \\
\hline 39 & $\mathrm{M}$ & 68 & Left colon & 2 & 2 & 0 & 12.2 & 100 & Yes & 62 \\
\hline 40 & $\mathrm{M}$ & 61 & Left colon & 2 & 1 & 0 & 15.5 & 100 & Yes & 69 \\
\hline 41 & $\mathrm{M}$ & 71 & Left colon & 1 & 1 & 0 & 15.5 & 100 & Yes & 36 \\
\hline 42 & $M$ & 81 & Left colon & 2 & 2 & 4.44 & 28.8 & 70 & Yes & 57 \\
\hline 43 & $M$ & 63 & Left colon & 2 & 2 & 2.22 & 15.5 & 30 & Yes & 62 \\
\hline 44 & $\mathrm{~F}$ & 76 & Left colon & 2 & 2 & 0 & 37.7 & 70 & Yes & 60 \\
\hline 45 & $M$ & 78 & Left colon & 1 & 2 & 10 & 14.4 & 100 & Yes & 57 \\
\hline 46 & $\mathrm{M}$ & 77 & Left colon & 2 & 2 & 0 & 17.7 & 100 & Yes & 9 \\
\hline 47 & $\mathrm{~F}$ & 76 & Left colon & 1 & 1 & 0 & 25.5 & 40 & Yes & 10 \\
\hline 48 & $\mathrm{~F}$ & 79 & Left colon & 2 & 2 & 5.55 & 4.44 & 100 & Yes & 20 \\
\hline 49 & $\mathrm{M}$ & 77 & Left colon & 2 & 2 & 0 & 0 & 10 & Yes & 37 \\
\hline 50 & $\mathrm{~F}$ & 75 & Left colon & 2 & 2 & 0 & 0 & 100 & Yes & 18 \\
\hline 51 & $M$ & 69 & Right colon & 2 & 2 & 0 & 0 & 100 & Yes & 12 \\
\hline 52 & $\mathrm{~F}$ & 69 & Left colon & 2 & 2 & 16.6 & 23.3 & 50 & Yes & 32 \\
\hline
\end{tabular}

$\mathrm{F}$, female; $\mathrm{M}$, male.

(figure 2A). Intratumoural D2-40 stained vessels were mainly found within ulcerated areas of the tumours (figure 2C); only $17 / 52$ carcinomas exhibited intratumoural vessels labelled by D2-40 antibody aside these areas (figure 2B). On the whole, the mean P-LVD of positive cases was higher than the mean I-LVD (17.40 vs 9.78). Moreover, high P-LVD was recorded in all the cases which had been submitted to conservative surgery (cases
40, 41, 44 and 47). Staining was evidenced within the cytoplasm and at the membrane of the endothelial cells of positive vessels; a cytoplasmic labelling was also present in the neoplastic cells of 6/52 tumours (cases 3, 13, 17, 23, 27, 46) (figure 3).

A significantly higher P-LVD was evidenced in colorectal carcinomas located at the left colon $(p=0.023)$ or characterised by high VEGF expression $(p=0.009)$ or disease progression during 
Table 2 Clinicopathological characteristics and immunohistochemical data of the two groups of patients (showing disease progression or not)

\begin{tabular}{|c|c|c|}
\hline \multirow[b]{2}{*}{ Parameter } & \multicolumn{2}{|l|}{ Patients } \\
\hline & $\begin{array}{l}\text { Absence of disease } \\
\text { progression }(n=23)\end{array}$ & $\begin{array}{l}\text { Disease progression } \\
(\mathrm{n}=29)\end{array}$ \\
\hline Mean age & $69.17 \pm 8.09$ & $70.55 \pm 5.9$ \\
\hline \multicolumn{3}{|l|}{ Sex } \\
\hline Male & 14 & 16 \\
\hline Female & 9 & 13 \\
\hline \multicolumn{3}{|l|}{ Site } \\
\hline Left colon & 14 & 22 \\
\hline Right colon & 9 & 7 \\
\hline \multicolumn{3}{|l|}{ Grade } \\
\hline G1 & 3 & 11 \\
\hline G2 & 18 & 17 \\
\hline G3 & 2 & 1 \\
\hline \multicolumn{3}{|l|}{$\mathrm{T}$} \\
\hline 1 & 1 & 4 \\
\hline 2 & 22 & 25 \\
\hline \multicolumn{3}{|c|}{ Vascular endothelial growth factor expression } \\
\hline Low $(0-50 \%$ positive cells) & 17 & 10 \\
\hline High (51-100\% positive cells) & 6 & 19 \\
\hline \multicolumn{3}{|c|}{ Peritumoural lymphatic vessel density } \\
\hline Low $\left(<10.54\right.$ vessels $\left./ \mathrm{mm}^{2}\right)$ & 17 & 9 \\
\hline High $\left(>10.54\right.$ vessels $\left./ \mathrm{mm}^{2}\right)$ & 6 & 20 \\
\hline \multicolumn{3}{|c|}{ Intratumoural lymphatic vessel density } \\
\hline 0 & 17 & 18 \\
\hline$>0$ & 6 & 11 \\
\hline
\end{tabular}

the follow-up ( $p=0.008$; power calculation: 0.74) (table 3). On the contrary, no statistically significant correlation emerged between I-LVD and the various clinicopathological parameters, VEGF expression or evidence of disease progression (table 4).

A Spearman correlation test showed that P-LVD but not I-LVD was positively significantly correlated with VEGF score $(r=0.465 ; \mathrm{p}=0.0005 ; \mathrm{CI}=0.220$ to 0.655$) \quad(\mathrm{r}=0.07 ; \mathrm{p}=0,6219 ;$ $\mathrm{CI}=-0.207$ to 0.336 ).

Univariate analyses revealed that high P-LVD ( $>10.54$ vessels/ $\mathrm{mm}^{2}$ ) (figure 4 ) as well as high VEGF expression ( $>50 \%$ of stained cells) were significantly negative prognostic parameters associ-

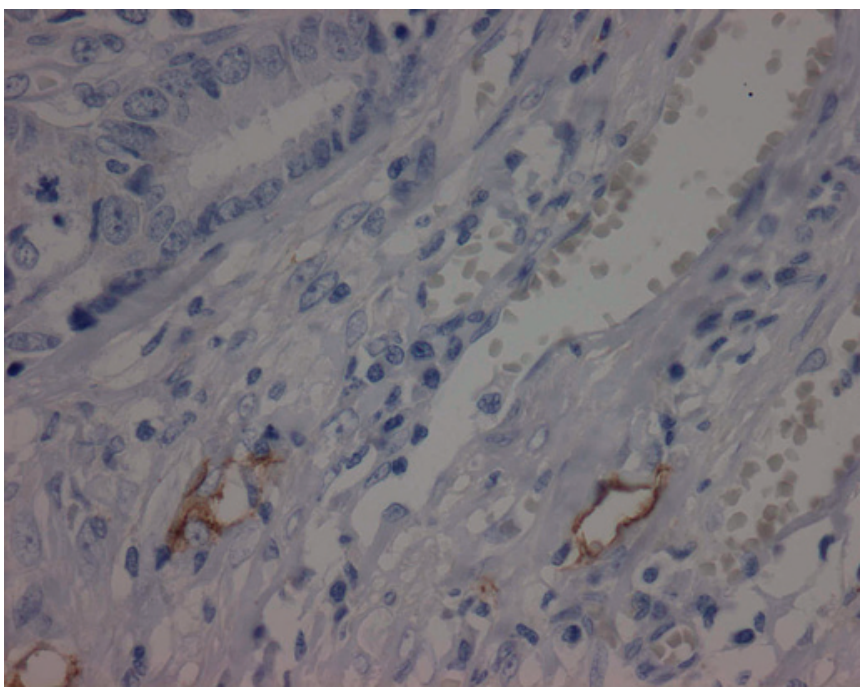

Figure 1 D2-40 antibody labelling in the endothelial cells of lymphatic vessels but not in those of haematic vessels (D2-40 stain; original magnification, $\times 200$ ).
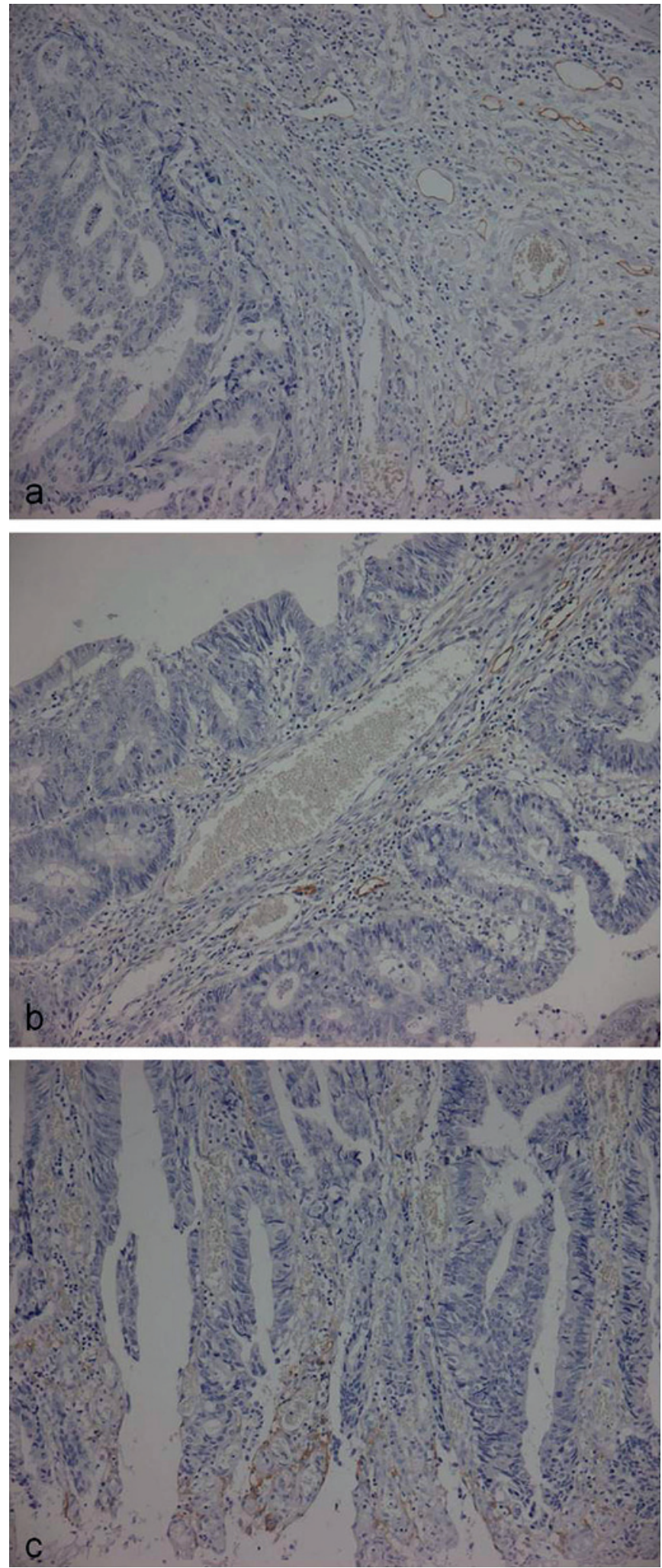

Figure 2 (A) Peritumoural (D2-40 stain; original magnification, $\times 100$ ) and (B) intratumoural lymphatic vessels (D2-40 stain; original magnification, $\times 100$ ) labelled by D2-40 antibody. (C) Intratumoural lymphatics within an ulcerated area of the tumour (D2-40 stain; original magnification, $\times 100$ ).

ated with a shorter disease-free interval in stage I colorectal cancer (table 5). Multivariate analysis indicated VEGF immunoexpression as the only independent prognostic parameter $(\mathrm{p}=0.0001)$ (table 5). 

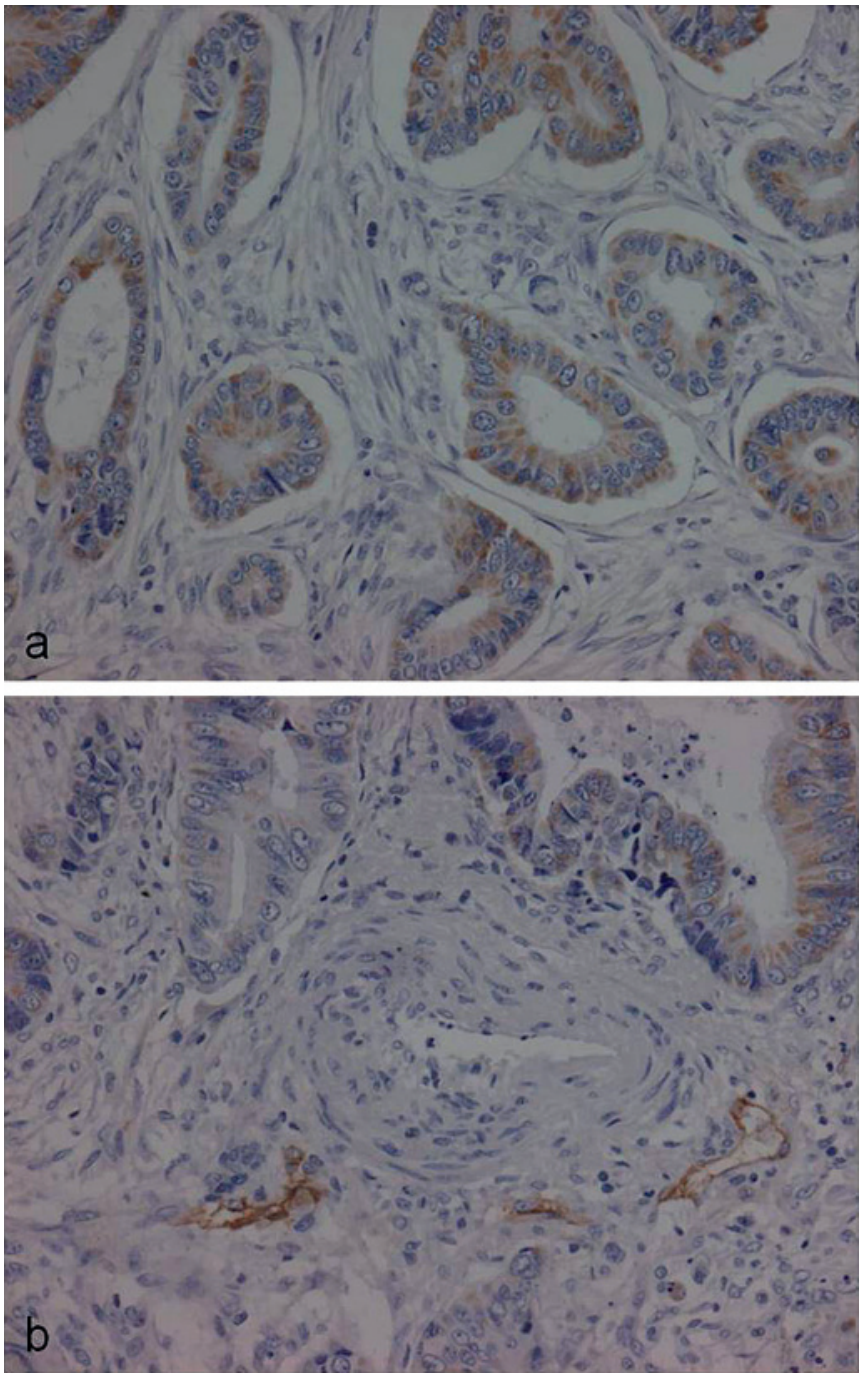

Figure 3 (A) D2-40 immunoexpression in the neoplastic cells of colorectal carcinoma (D2-40 stain; original magnification, $\times 200$ ). (B) Staining in adjacent lymphatic vessels, serving as a positive control for the immunoreaction (D2-40 stain; original magnification, $\times 100$ ).

\section{DISCUSSION}

In most countries, patients with stage I colorectal cancer do not receive adjuvant systemic therapy, since the reported 5-year survival rate is around $80-90 \%{ }^{145}$ and meaningful survival benefits related to chemotherapy have not been proven for these neoplasias. $^{24}$ Nevertheless, disease progression leading to patients death has been reported in a percentage of these neoplasias. ${ }^{4}$ This event may depend upon postsurgical understaging of colorectal carcinoma. Indeed, node-negative status may be erroneously documented due to variable number of nodes harvested and microscopically assessed for the presence of metastases $^{25}$ or to the current recommendations to examine microscopically only one slide from each node. ${ }^{26}$ Furthermore, the increasing use of conservative local excision techniques for low rectal carcinomas provides no regional nodes for histological assessment. Thus, additional factors predicting the individual progression risk of stage I colorectal carcinoma are needed in order to provide high-risk patients with adjuvant systemic treatment and to avoid overtreatment and unnecessary complications due to adverse effects of therapy in low-risk patients.
Table 3 Statistical correlations between peritumoural lymphatic vessel density and the various clinicopathological parameters of the 52 analysed colorectal carcinomas, investigated using Mann-Whitney and Kruskall-Wallis tests

\begin{tabular}{|c|c|c|c|c|}
\hline Parameter & $\mathbf{n}$ & $\begin{array}{l}\text { Mean } \\
\text { rank }\end{array}$ & $\begin{array}{l}95 \% \mathrm{Cl} \text { for } \\
\text { the median }\end{array}$ & p Value \\
\hline \multicolumn{5}{|l|}{ Sex } \\
\hline Male & 30 & 26.21 & 0 to 15.5 & \multirow[t]{2}{*}{0.871} \\
\hline Female & 22 & 26.88 & 0 to 16.75 & \\
\hline \multicolumn{5}{|l|}{ Age } \\
\hline$\leq 70$ & 26 & 27.82 & 5.65 to 15.5 & \multirow[t]{2}{*}{0.527} \\
\hline$>70$ & 26 & 25.17 & 0 to 15.5 & \\
\hline \multicolumn{5}{|l|}{ Site } \\
\hline Left colon & 36 & 29.68 & 7.39 to 15.87 & \multirow[t]{2}{*}{0.023} \\
\hline Right colon & 16 & 19.34 & 0 to 12.59 & \\
\hline \multicolumn{5}{|l|}{ Grade } \\
\hline 1 & 14 & 31.14 & & \multirow[t]{3}{*}{0.294} \\
\hline 2 & 35 & 24.27 & $N A^{*}$ & \\
\hline 3 & 3 & 30.83 & & \\
\hline \multicolumn{5}{|l|}{$\mathrm{T}$} \\
\hline $\mathrm{T} 1$ & 5 & 31.4 & NA† & \multirow[t]{2}{*}{0.447} \\
\hline T2 & 47 & 25.97 & 0 to 14.05 & \\
\hline \multicolumn{5}{|c|}{ Vascular endothelial growth factor expression } \\
\hline Low $(0-50 \%$ positive cells) & 27 & 21.35 & 0 to 12.2 & \multirow[t]{2}{*}{0.009} \\
\hline High (51-100\% positive cells) & 25 & 32.06 & 8.42 to 17.53 & \\
\hline \multicolumn{5}{|l|}{ Disease progression } \\
\hline Not & 23 & 20.3 & 0 to 8.8 & \multirow[t]{2}{*}{0.008} \\
\hline Yes & 29 & 31.41 & 11.16 to 16.85 & \\
\hline
\end{tabular}

*Not available for comparison of three groups.

†Not available for small sample.

Patients with colorectal cancer at risk for disease progression may be identified by tumour features known to determine the process of invasion and metastasis. The assessment of LVD has been shown to be of prognostic utility in determining the

Table 4 Statistical correlations between intratumoural lymphatic vessel density and the various clinicopathological parameters of the 52 analysed colorectal carcinomas, investigated using Mann-Whitney and Kruskall-Wallis tests

\begin{tabular}{|c|c|c|c|c|}
\hline Parameter & $\mathbf{n}$ & $\begin{array}{l}\text { Mean } \\
\text { rank }\end{array}$ & $\begin{array}{l}95 \% \mathrm{Cl} \text { for } \\
\text { the median }\end{array}$ & p Value \\
\hline \multicolumn{5}{|l|}{ Sex } \\
\hline Male & 30 & 25.18 & 0 to 0 & \multirow[t]{2}{*}{0.388} \\
\hline Female & 22 & 28.29 & 0 to 7.87 & \\
\hline \multicolumn{5}{|l|}{ Age } \\
\hline$\leq 70$ years & 26 & 29.53 & 0 to 8.8 & \multirow[t]{2}{*}{0.088} \\
\hline$>70$ years & 26 & 23.41 & 0 to 0 & \\
\hline \multicolumn{5}{|l|}{ Site } \\
\hline Left colon & 36 & 28.65 & 0 to 5.92 & \multirow[t]{2}{*}{0.0703} \\
\hline Right colon & 16 & 21.65 & 0 to 0 & \\
\hline \multicolumn{5}{|l|}{ Grade } \\
\hline 1 & 14 & 27.54 & & \multirow[t]{3}{*}{0.884} \\
\hline 2 & 35 & 25.91 & $N A^{*}$ & \\
\hline 3 & 3 & 28.5 & & \\
\hline \multicolumn{5}{|l|}{$T$} \\
\hline $\mathrm{T} 1$ & 5 & 18 & NA† & \multirow[t]{2}{*}{0.1202} \\
\hline T2 & 47 & 27.4 & 0 to 1.51 & \\
\hline \multicolumn{5}{|c|}{ Vascular endothelial growth factor expression } \\
\hline Low $(0-50 \%$ positive cells) & 27 & 27 & 0 to 2.42 & \multirow[t]{2}{*}{0.77} \\
\hline High (51-100\% positive cells) & 25 & 25.96 & 0 to 3.78 & \\
\hline \multicolumn{5}{|l|}{ Disease progression } \\
\hline Not & 23 & 24.84 & 0 to 0 & \multirow[t]{2}{*}{0.409} \\
\hline Yes & 29 & 27.81 & 0 to 04.69 & \\
\hline
\end{tabular}

*Not available for comparison of three groups.

†Not available for a small sample. 


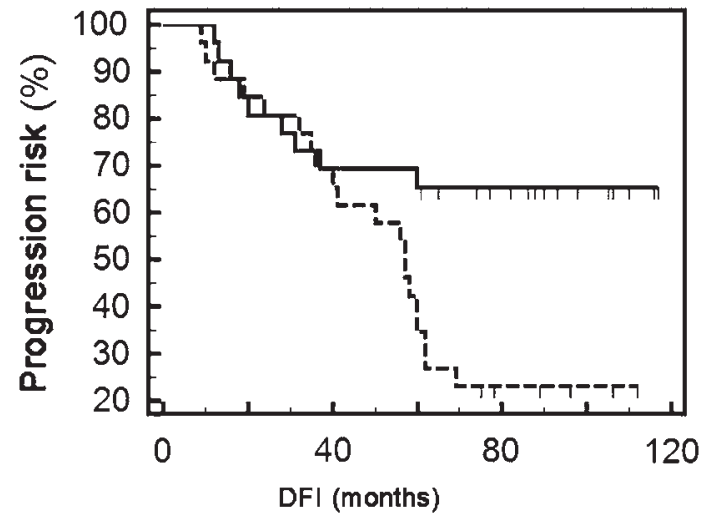

P-LVD

- Low (< 10.54 vimm2) …-........ High (> 10.54 v/mm2)

Figure 4 Kaplan-Meier progression-free survival curve according to peritumoral lymphatic vessel density (P-LVD). Progression risk was significantly higher for colorectal carcinomas characterised by high P-LVD (>10.54 vessels $/ \mathrm{mm}^{2}$ ) than for cases with low P-LVD. DFI, disease-free interval.

metastatic risk of several common human tumours. ${ }^{27-30}$ Its clinical significance has also been widely examined in colorectal carcinoma, ${ }^{11-19}$ though with controversial results. Indeed, some studies demonstrated the role of LVD as an indicator of metastasis or patient survival, ${ }^{14-1618} 19$ while others could not confirm the findings. ${ }^{13} 1731$ Divergent results may be attributed to the difference in the various antibodies used in the various studies, and to the difference in the techniques of immunostaining and LVD quantification. ${ }^{20}$ A recent study performed using D2-40, which has been demonstrated to be more sensitive in detecting lymphatic endothelium than other markers such as Prox1 or LYVE- $1,{ }^{32}$ has shown that LVD behaves as a significant independent prognostic factor for recurrence risk of node-negative colorectal carcinoma. ${ }^{18}$ As these authors mainly analysed stage II carcinomas, with stage I tumours representing only $6 \%$ of total, ${ }^{18}$ we thought it would be interesting to test the prognostic significance of LVD on the progression risk of stage I colorectal cancer. Thus, herein we evaluated intra- and peritumoural LVD in a series of 52 stage I colorectal carcinomas including cases from patients showing disease progression within 5 years from the initial diagnosis and from patients still alive with no evidence of disease progression after 5 years from curative surgery. We aimed

Table 5 Univariate and multivariate analyses for overall survival in 52 TNM stage I colorectal carcinomas

\begin{tabular}{|c|c|c|c|c|c|}
\hline Parameter & $\chi^{2}$ & df & p Value & $95 \% \mathrm{Cl}$ & HR \\
\hline \multicolumn{6}{|l|}{ Univariate analysis } \\
\hline Sex & 0.2544 & 1 & 0.614 & 0.5736 to 2.5303 & 1.2047 \\
\hline Age & 1.4285 & 1 & 0.232 & 0.7449 to 3.2252 & 1.55 \\
\hline Site & 0.7168 & 1 & 0.397 & 0.3177 to 1.5250 & 0.696 \\
\hline Grade & 5.0021 & 2 & 0.082 & $N A^{*}$ & \\
\hline $\mathrm{T}$ & 1.8605 & 1 & 0.172 & 1.1206 to 1.9904 & 0.1726 \\
\hline $\begin{array}{l}\text { Peritumoural lymphatic } \\
\text { vessel density }\end{array}$ & 6.29 & 1 & 0.0121 & 1.2543 to 5.4030 & 2.6032 \\
\hline $\begin{array}{l}\text { Intratumoural lymphatic } \\
\text { vessel density }\end{array}$ & 0.4354 & 1 & 0.509 & 0.5887 to 2.7933 & 1.2824 \\
\hline $\begin{array}{l}\text { Vascular endothelial } \\
\text { growth factor }\end{array}$ & 7.21 & 1 & 0.007 & 1.2927 to 5.6718 & 2.7078 \\
\hline \multicolumn{6}{|l|}{ Multivariate analysis } \\
\hline Parameter & $\beta$ & SE & $\operatorname{Exp}(\beta)$ & $95 \% \mathrm{Cl}$ of $\exp (\beta)$ & $\mathrm{p}$ Value \\
\hline $\begin{array}{l}\text { Vascular endothelial } \\
\text { growth factor }\end{array}$ & 0.025 & 0.0065 & 1.0254 & 1.0124 to 1.0385 & 0.0001 \\
\hline
\end{tabular}

*Not available for comparison of three groups. at testing the hypothesis that diverse biological behaviour in these subgroups of patients might depend upon a difference in the quantity of lymphangiogenesis which could have increased the metastatic potential of their tumours

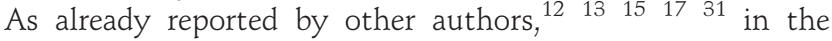
analysed cases I-LVD was lower than P-LVD. Moreover, significantly higher P-LVD counts, but not I-LVD, were observed in the colorectal carcinomas characterised by disease progression in comparison with non-progressing cases. Finally, P-LVD, but not I-LVD, appeared as a negative, though not independent, significant prognostic factor associated with high progression risk of stage I colorectal cancer. Thus, our findings are in accordance with those reported by Dohekie et al ${ }^{18}$ on stage II colorectal cancer, though these authors did not differentiate between I-LVD and P-LVD. ${ }^{18}$ We may speculate that a high density of peritumoural lymphatic vessels may increase the probability of tumour cells dissemination, whereby the number of intratumoural lymphatic vessels would not influence the metastatic risk of stage I colorectal cancer. Besides, some impressive studies have questioned the functional activity of intratumoural lymphatics due to the high compressive forces existing within solid tumours, ${ }^{33} 34$ and it has been suggested that functional lymphatics in the tumour margin are sufficient for lymphatic metastasis. ${ }^{33}$ Furthermore, Longhatto-Filho and colleagues ${ }^{19}$ have recently reported that P-LVD but not I-LVD correlates with colorectal carcinoma poor outcome markers.

Members of the vascular endothelial growth factor (VEGF) family of molecules, and specifically VEGF-C and VEGF-D, represent the most studied lymphangiogenic factors. Despite its initial recognition as a potent factor in haemangiogenesis, VEGFA has also been shown to induce intra- and peritumoural lymphangiogenesis in transgenic and xenographic mouse tumour models and to promote lymph-node metastasis. ${ }^{35} 36$ It can act both indirectly via the recruitment of VEGFC/Dproducing inflammatory cells ${ }^{37}$ and directly via its receptor (VEGFR-2), ${ }^{38}$ which is expressed on lymphatic endothelial cells. Herein, we found that VEGF expression is positively significantly correlated with P-LVD, which suggest its action as a proangiogenic mediator in stage I colorectal cancer, similarly to that reported in other neoplasias. ${ }^{39}$ Lack of correlation with I-LVD, as we evidenced, may depend upon the exclusion of the lymphatic vessels present in the ulcerated or necrotic areas in the assessment of I-LVD itself.

Our immunohistochemical analysis also evidenced D2-40 immunoexpression in the neoplastic cells of six out of 52 colorectal carcinomas. D2-40 has been suggested as a marker of cancer stem cells in squamous-cell carcinomas. ${ }^{40}$ To the best of our knowledge, expression of this protein had been previously

\section{Take-home messages}

Peritumoural, but not intratumoural, lymphatic vessel density is a negative prognostic factor associated with a significantly higher progression risk in stage I colorectal carcinoma.

- The existence of a positive significant correlation between VEGF-A expression and P-LVD suggests a VEGF-A-mediated regulation of lymphangiogenesis in the early-stage colorectal cancer.

- If our findings are to be confirmed, the assessment of P-LVD on histological sections might represent a tool to identify stage I colorectal carcinomas at higher risk of progression in order to submit them to adjuvant therapies. 
reported in colorectal cancer-derived cells only in one study. ${ }^{41}$ The small number of positive cases which we found herein did not allow us to draw any conclusions on the possible significance of D2-40 expression in colorectal carcinoma. Nonetheless, in consideration of its suggested role as a mediator of tumour cell invasion and metastasis in other neoplasias, ${ }^{42}$ further studies are needed in order to clarify the eventual role of tumour cell-derived D2-40 in colorectal cancer.

In conclusion, this pilot study shows for the first time that a high density of peritumoural lymphatic vessels represents a negative prognostic marker, associated with a shorter diseasefree interval, in stage I colorectal carcinoma. If our findings are further validated, the assessment of P-LVD on surgical specimens might be used as a tool to identify those patients at higher risk of disease progression in order to submit them to adjuvant therapies. The insignificance of P-LVD as an independent prognostic factor may reside on its VEGF-A-dependent regulation in stage I colorectal carcinoma as we evidenced; indeed, the expression of this factor was found to be an independent prognostic variable for progression-free and overall survival of stage I colorectal cancer. ${ }^{22}$ Thus, it is tempting to speculate that therapies targeting this factor might be used in order to reduce lymphangiogenesis and the progression risk of this neoplasia.

\section{Competing interests None.}

Patient consent Obtained.

Ethics approval Ethics approval was provided by the Local Ethics Committee of University of Messina.

Provenance and peer review Not commissioned; externally peer reviewed.

\section{REFERENCES}

1. Landis SH, Murray T, Bolden S. Cancer statistics. Cancer J Clin 1999;49:8-31.

2. Wiggers T, Arends JW, Schutter B, et al. A multivariate analysis of pathologic prognostic indicators in large bowel cancer. Cancer 1988;61:386-9.

3. Wu XC, Chen WW, Steele B, et al. Subsite-specific incidence rate and stage of disease in colorectal cancer by race, gender, and age group. Cancer 2001;92:2547-54

4. Di Gregorio C, Fante R, Roncucci L, et al. Clinical features, frequency and prognosis of Dukes' A colorectal carcinoma: a population-based investigation. Eur J Cancer 1996;32A:1957-62.

5. Wichmann MW, Muller C, Hornung HM. The Colorectal Cancer study Group. Results of long-term follow-up after curative resection of Dukes' A colorectal cancer. World J Surg 2002;26:732-6.

6. Compton CC, Greene FL. The staging of colorectal cancer: 2004 and beyond. CA Cancer J Clin 2004;54:295-308.

7. Reis-Filho JS, Schmitt FC. Lymphangiogenesis in tumors: what do we know? Microsc Res Tech 2003:60:171-80.

8. Mandriota SJ, Jussila L, Jeltsch M, et al. Vascular endothelial growth factor-Cmediated lymphangiogenesis promotes tumour metastasis. EMBO J 2001:20:672-82.

9. Skobe $\mathbf{M}$, Hawighorst $\mathrm{T}$, Jackson DG, et al. Induction of tumor lymphangiogenesis by VEGF-C promotes breast cancer metastasis. Nat Med 2001;7:192-8.

10. Stacker SA, Caesar C, Baldwin ME, et al. VEGF-D promotes the metastatic spread of tumor cells via the lymphatics. Nat Med 2001;7:186-91.

11. Ohno M, Nakamura T, Kunimoto $Y$, et al. Lymphagenesis correlates with expression of vascular endothelial growth factor-C in colorectal cancer. Oncol Rep 2002; 10:939-43.

12. Liang $\mathbf{P}$, Hong JW, Ubukata $\mathrm{H}$, et al. Increased density and diameter of lymphatic microvessels correlate with lymph node metastasis in early stage invasive colorectal carcinoma. Virchows Arch 2006;448:570-5.

13. Gao J, Knutsen A, Arbman G, et al. Clinical and biological significance of angiogenesis and lymphangiogenesis in colorectal cancer. Digest Liv Dis 2009;41:116-22.

14. Saad RS, Kordunsky L, Liu YL, et al. Lymphatic microvessel density as prognostic marker in colorectal cancer. Mod Pathol 2006;19:1317-23.

15. Kaneko I, Tanaka S, Oka S, et al. Lymphatic vessel density at the site of deepest penetration as a predictor of lymph node metastasis in submucosal colorectal cancer. Dis Colon Rectum 2007;50:13-21.
16. Matsumoto $\mathbf{K}$, Nakayama $Y$, Inoue $Y$, et al. Lymphatic microvessel density is an independent prognostic factor in colorectal cancer. Dis Colon Rectum 2007:50:308-14

17. Omachi T, Kawai $Y$, Mizuno R, et al. Immunohistochemical demonstration of proliferating lymphatic vessels in colorectal carcinoma and its clinicopathological significance. Cancer Lett 2007:246:167-72.

18. Doekhie FS, Morreau H, de Bock GH, et al. Expression and lymphatic microvesse density in primary tumors of node-negative colorectal cancer patients predict disease recurrence. Cancer Microenviron 2008:1:141-51.

19. Longatto-Filho A, Pinheiro C, Ferreira L, et al. Peritumoural, but not intratumoural lymphatic vessel density and invasion correlate with colorectal carcinoma poor-outcome markers. Virchows Arch 2008:452:133-8.

20. Royston D, Jackson DG. Mechanisms of lymphatic metastasis in human colorecta adenocarcinoma. J Pathol 2009;217:608-19.

21. Sobin LH, Wittekind C, eds. TNM Classification of Malignant Tumors In: International Union Against Cancer (UICC). 6th edn. New York: Wiley-Liss, 2002.

22. Barresi V, Di Gregorio C, Regiani-Bonetti L, et al. Stage I colorectal carcinoma: VEGF immunohistochemical expression, microvessel density, and their correlation with clinical outcome. Virchows Arch 2010:457:11-19.

23. Weidner N, Semple JP, Welch WR, et al. Tumor angiogenesis and metastasis-correlation in invasive breast carcinoma. $\mathrm{N} \mathrm{Engl} \mathrm{J} \mathrm{Med}$ 1991:324:1-8.

24. Moertel CG, Fleming TR, Macdonald JS, et al. Levamisole and fluorouracil for adjuvant therapy of resected colon carcinoma. N Engl J Med 1990; 322:352-8.

25. Swanson RS, Compton CC, Stewart AK, et al. The prognosis of T3NO colon cance is dependent on the number of lymph nodes examined. Ann Surg Oncol 2003; 10:65-71.

26. Williams GT, Quirke P, Shepherd NA. Dataset for Colorectal Cancer. 2nd edn London: The Royal College of Pathologists, 2007.

27. Straume $\mathbf{0}$, Jackson DG, Akslen LA. Independent prognostic impact of lymphatic vessel density and presence of low-grade lymphangiogenesis in cutaneous melanoma. Clin Cancer Res 2003:9:250-6.

28. Kyzas PA, Geleff S, Batistatou A, et al. Evidence for lymphangiogenesis and its prognostic implications in head and neck squamous cell carcinoma. J Pathol 2005;206:170-7

29. Miyata Y, Kanda S, Ohba K, et al. Lymphangiogenesis and angiogenesis in bladder cancer: prognostic implications and regulation by vascular endothelial growth factors A, C, and D. Clin Cancer Res 2006;12:800-6.

30. Renyi-Vamos F, Tovari J, Fillinger J, et al. Lymphangiogenesis correlates with lymph node metastasis, prognosis, and angiogenic phenotype in human non-small cell lung cancer. Clin Cancer Res 2005;11:7344-53.

31. Duff SE, Jeziorska M, Kumar S, et al. Lymphatic vessel density, microvessel density and lymphangiogenic growth factor expression in colorectal cancer. Colorectal Dis 2007:9:793-800

32. Van der Auwera I, Van den Eynden GG, Colpaert CG, et al. Tumor lymphangiogenesis in inflammatory breast carcinoma: a histomorphometric study. Clin Cancer Res 2005;11:7637-42.

33. Padera TP, Kadambi A, di Tomaso E, et al. Lymphatic metastasis in the absence of functional intratumor lymphatics. Science 2002;296:1883-6.

34. Padera TP, Stoll BR, Tooredman JB, et al. Pathology: cancer cells compress intratumour vessels. Nature 2004:427:695.

35. Hirakawa S, Kodama S, Kunstfeld R, et al. VEGF-A induces tumor and sentinel lymph node lymphangiogenesis and promotes lymphatic metastasis. J Exp Med 2005:201:1089-99.

36. Bjorndahl MA, Cao R, Burton JB, et al. Vascular endothelial growth factor-a promotes peritumoral lymphangiogenesis and lymphatic metastasis. Cancer Res 2005:65:9261-8

37. Cursiefen C, Chen L, Borges LP, et al. VEGF-A stimulates lymphangiogenesis and hemangiogenesis in inflammatory neovascularization via macrophage recruitment. J Clin Invest 2004;113:1040-50.

38. Hong YK, Lange-Asschenfeldt B, Velasco P, et al. VEGF-A promotes tissue repairassociated lymphatic vessel formation via VEGFR-2 and the $\alpha 1 \beta 1$ and $\alpha 2 \beta 1$ integrins. FASEB J 2004;18:1111-13

39. Kadowaki I, Ichinohasama $\mathrm{R}$, Harigae $\mathrm{H}$, et al. Accelerated lymphangiogenesis in malignant lymphoma: possible role of VEGF-A and VEGF-C. Br J Haematol 2005; 130:869-77.

40. Atsumi N, Ishii G, Kijima M, et al. Podoplanin a novel marker of tumor-initiating cells in human squamous cell carcinoma A431. Biochem Biophys Res Commun 2008;373:36-41

41. Kono T, Shimoda M, Takahashi M, et al. Immunohistochemical detection of the lymphatic marker podoplanin in diverse types of human cancer cells using a novel antibody. Int J Oncol 2007:31:501-8.

42. Wicki A, Christofori $G$. The potential role of podoplanin in tumor invasion. $\mathrm{Br} J$ Cancer 2007:96:1-5. 